\title{
Metabolically stressed adipocytes: mediators of cardioprotection via extracellular vesicle-mediated transport of oxidatively damaged mitochondria
}

\author{
Sarah R. Anthony, Michael Tranter \\ Division of Cardiovascular Health and Disease, Department of Internal Medicine, University of Cincinnati College of Medicine, Cincinnati, OH, USA \\ Correspondence to: Michael Tranter, PhD. Division of Cardiovascular Health and Disease, Department of Internal Medicine, University of Cincinnati \\ College of Medicine, Cincinnati, OH 45267, USA. Email: Michael.Tranter@UC.edu. \\ Comment on: Crewe C, Funcke JB, Li S, et al. Extracellular vesicle-based interorgan transport of mitochondria from energetically stressed adipocytes. \\ Cell Metab 2021;33:1853-1868.e11.
}

Received: 04 December 2021; Accepted: 17 December 2021; Published: 25 January 2022.

doi: $10.21037 /$ exrna-21-31

View this article at: https://dx.doi.org/10.21037/exrna-21-31

Obesity is a known risk factor for cardiovascular disease (CVD), including heart failure and ischemia. However, although the incidence of CVD is higher in obese humans, numerous studies have found that obese individuals with CVD have a better prognosis than lean individuals, a phenomenon known as the "obesity paradox" (1). Adipose tissue has a well-defined role as an endocrine organ that differs by anatomical location [e.g., inguinal white adipose tissue (WAT), perigonadal WAT, interscapular brown adipose tissue (BAT), etc.] as well as adipocyte cell content (white $v s$. brown $v s$. beige), and recent work has focused on the adipose-cardiac signaling axis to decipher the endocrine mechanisms of adipocytes. We and others have recently reviewed adipose tissue-derived signals that are known to directly impact the myocardium (2-4). Some of these adipose-derived endocrine signals are mediated by small extracellular vesicles (sEVs) that can deliver diverse cargo, including RNA, protein, and lipids (4). However, the cardiac effect of adipose-derived sEVs is not always consistent. Multiple recent studies describe EV-mediated delivery of specific microRNA (miRNA) from adiposederived stem cells that impact mouse models of cardiac ischemic injury (5-9). BAT-derived EVs blunt obesityinduced declines in cardiac function, but their delivered $\mathrm{EVs}$ were shown to accumulate mainly in the liver, spleen, and lungs, and the direct effects on the myocardium were not investigated (10). Conversely, EVs secreted from WAT in response to PPAR $\gamma$ activation induce hypertrophic signaling in neonatal cardiac myocytes via transport of miRNA (11).
$\mathrm{sEV}$ s isolated from epicardial adipose tissue were associated with atrial fibrillation in humans, were sufficient to induce cardiac fibrosis when injected into rats, and implicated sEVmediated delivery of pro-fibrotic miRNAs as a potential mechanism (12).

In a recent issue of Cell Metabolism, Crewe et al. (13) examined the role of sEVs released by energetically stressed adipocytes, and their effects on cardiomyocytes. They have previously shown that mice with an adipocyte-specific overexpression of mitochondrial ferritin (adipo-FtMT), when placed on high fat diet (HFD), display dysfunction in multiple organ systems, including mitochondrial oxidative stress in the heart (14). As cardiac oxidative stress is also observed in obese humans, they extended these prior observations in this work to specifically examine circulating $\mathrm{sEVs}$ as endocrine mediators in adipo-FtMT mice (13). They first demonstrated that adipo-FtMT mice produce more sEVs than their wild-type counterparts, and that inhibiting $\mathrm{sEV}$ release via neutral sphingomyelinase ablates the observed cardiac oxidative stress. Isolated circulating sEVs from adipo-FtMT mice also induced an increase in oxidative stress in healthy (wild-type) primary cardiomyocytes in culture, compared to cardiomyocytes treated with $\mathrm{sEV}$ s from healthy mice. Additional models of mitochondrial stress in stromal vascular fraction (SVF)derived adipocytes, including palmitate treatment, electron transport chain inhibitors, and HFD feeding of the mice prior to SVF isolation, were also seen to increase sEV release, confirming that $\mathrm{sEV}$ release is a general response 
to oxidative stress. Furthermore, sEVs derived from oxidatively stressed adipocytes were found to be respirationcompetent and enriched for mitochondrial proteins. Importantly, injection of these stressed sEVs into wild-type mice 2 hours prior to cardiac ischemia/reperfusion (I/R) injury reduced acute myocardial infarct size, resulting in less cardiac hypertrophy and increased ejection fraction at seven days post-infarct. Thus, the authors concluded that the mild $\mathrm{sEV}$-induced oxidative stress in the myocardium serves as a cardioprotective preconditioning effect against subsequent I/R injury.

This work is novel in that it shows a direct endocrinedriven cardioprotective signal being generated by adipose tissue through the $\mathrm{sEV}$-mediated transfer of mitochondria. Interestingly, this work links metabolically stressed adipose tissue, potentially through a mechanistic mediator of the obesity paradox, with long-standing evidence that increasing ROS signaling in the heart prior to I/R elicits a protective preconditioning response. ROS generation within the myocardium was first shown to be a mediator of cardioprotection via ischemic preconditioning by Sun et al. (15) in 1996, and it was later shown that mitochondria were a likely key source of this ROS (16). Prior work by Haar et al. (17) also showed that acute feeding of HFD elicited a cardiac preconditioning phenotype in mice, but the role of sEVs was not explored in this model, and the cardioprotective effect of HFD was fleeting and waned after 6 weeks of HFD. Many cardiac preconditioning stimuli are accepted to mediate an acute (early-minutes to hours) and/or more sustained (late-hours to days) phase of preconditioning. In light of this, it would be interesting to see whether sEVs derived from metabolically stressed adipocytes provide chronic protection, or display a distinct window of cardioprotection as observed from HFD by Haar et al. (17). This may be difficult to achieve via chronic sEV injection, but could possibly be done using an sEV secretion inhibitor in HFD-fed mice or directly in adipo-FtMT mice, for which cardiac infarct data was not reported.

There is little doubt from their work that the transfer of mitochondria is a mechanistic driver of the observed effects, but the work by Crewe et al. (13) also raises additional questions. For example, adipose-derived sEVs are known to elicit cardioprotection by transport of functional RNAs, such as miRNAs. Differential stress-induced sEV loading of RNA cargo was not characterized in this model. Application of an ROS scavenger, or alternative means to directly reduce ROS production in the heart prior to or during $\mathrm{I} / \mathrm{R}$, would have also allowed for conclusive demonstration that
$\mathrm{sEV}$-induced ROS generation within the myocardium is responsible for initiating the observed cardioprotection.

This work is also of particular interest to my laboratory as we recently demonstrated that adipocyte-specific deletion of the RNA binding protein HuR (Adipo-HuR ${ }^{-/}$) elicits spontaneous cardiac hypertrophy and fibrosis (18), and additionally have expertise in the field of cardiac preconditioning (19) and ischemic injury (20,21). Results from our Adipo-HuR ${ }^{-/-}$mice are suggestive of an endocrine $\mathrm{EV}$ driven mechanism of cardiac pathology, and work is ongoing to characterize the HuR-dependent cargo loading of Adipo-EVs from these mice, but given its nature as an RNA binding protein, the mediating factors are likely to be RNA.

This work by Crewe et al. (13) is likely just the tip of the iceberg with regard to how adipose tissue-derived endocrine signaling via EVs affects physiological homeostasis in other organ systems. The mechanisms that mediate adipo-EV protein and RNA cargo selection and how these pathways are altered under pathophysiological conditions such as obesity or metabolic syndrome remain largely unexplored.

\section{Acknowledgments}

Funding: SRA and MT are supported by NIH R01HL132111 and AHA TPA34910086.

\section{Footnote}

Provenance and Peer Review: This article was commissioned by the editorial office, ExRNA. The article has undergone external peer review.

Conflicts of Interest: Both authors have completed the ICMJE uniform disclosure form (available at https://exrna. amegroups.com/article/view/10.21037/exrna-21-31/coif). The authors have no conflicts of interest to declare.

Ethical Statement: The authors are accountable for all aspects of the work in ensuring that questions related to the accuracy or integrity of any part of the work are appropriately investigated and resolved.

Open Access Statement: This is an Open Access article distributed in accordance with the Creative Commons Attribution-NonCommercial-NoDerivs 4.0 International License (CC BY-NC-ND 4.0), which permits the noncommercial replication and distribution of the article with the strict proviso that no changes or edits are made and the 
original work is properly cited (including links to both the formal publication through the relevant DOI and the license). See: https://creativecommons.org/licenses/by-nc-nd/4.0/.

\section{References}

1. Lavie CJ, McAuley PA, Church TS, et al. Obesity and cardiovascular diseases: implications regarding fitness, fatness, and severity in the obesity paradox. J Am Coll Cardiol 2014;63:1345-54.

2. Gutiérrez-Cuevas J, Sandoval-Rodriguez A, Meza-Rios A, et al. Molecular Mechanisms of Obesity-Linked Cardiac Dysfunction: An Up-Date on Current Knowledge. Cells 2021;10:629.

3. Anthony SR, Guarnieri AR, Gozdiff A, et al. Mechanisms linking adipose tissue inflammation to cardiac hypertrophy and fibrosis. Clin Sci (Lond) 2019;133:2329-44.

4. Scheja L, Heeren J. The endocrine function of adipose tissues in health and cardiometabolic disease. Nat Rev Endocrinol 2019;15:507-24.

5. Zhu D, Wang Y, Thomas M, et al. Exosomes from adipose-derived stem cells alleviate myocardial infarction via microRNA-31/FIH1/HIF-1 $\alpha$ pathway. J Mol Cell Cardiol 2022;162:10-9.

6. Wang X, Zhu Y, Wu C, et al. Adipose-Derived Mesenchymal Stem Cells-Derived Exosomes Carry MicroRNA-671 to Alleviate Myocardial Infarction Through Inactivating the TGFBR2/Smad2 Axis. Inflammation 2021;44:1815-30.

7. Lai TC, Lee TL, Chang YC, et al. MicroRNA-221/222 Mediates ADSC-Exosome-Induced Cardioprotection Against Ischemia/Reperfusion by Targeting PUMA and ETS-1. Front Cell Dev Biol 2020;8:569150.

8. Deng S, Zhou X, Ge Z, et al. Exosomes from adiposederived mesenchymal stem cells ameliorate cardiac damage after myocardial infarction by activating S1P/SK1/S1PR1 signaling and promoting macrophage M2 polarization. Int J Biochem Cell Biol 2019;114:105564.

9. Cui X, He Z, Liang Z, et al. Exosomes From Adiposederived Mesenchymal Stem Cells Protect the Myocardium Against Ischemia/Reperfusion Injury Through Wnt/ $\beta$-Catenin Signaling Pathway. J Cardiovasc Pharmacol 2017;70:225-31.

10. Zhou X, Li Z, Qi M, et al. Brown adipose tissue-derived exosomes mitigate the metabolic syndrome in high fat diet mice. Theranostics 2020;10:8197-210.

11. Fang X, Stroud MJ, Ouyang K, et al. Adipocyte-specific loss of PPAR $\gamma$ attenuates cardiac hypertrophy. JCI Insight 2016;1:e89908.

12. Shaihov-Teper O, Ram E, Ballan N, et al. Extracellular Vesicles From Epicardial Fat Facilitate Atrial Fibrillation. Circulation 2021;143:2475-93.

13. Crewe C, Funcke JB, Li S, et al. Extracellular vesicle-based interorgan transport of mitochondria from energetically stressed adipocytes. Cell Metab 2021;33:1853-1868.e11.

14. Kusminski CM, Ghaben AL, Morley TS, et al. A Novel Model of Diabetic Complications: Adipocyte Mitochondrial Dysfunction Triggers Massive $\beta$-Cell Hyperplasia. Diabetes 2020;69:313-30.

15. Sun JZ, Tang XL, Park SW, et al. Evidence for an essential role of reactive oxygen species in the genesis of late preconditioning against myocardial stunning in conscious pigs. J Clin Invest 1996;97:562-76.

16. Vanden Hoek TL, Becker LB, Shao Z, et al. Reactive oxygen species released from mitochondria during brief hypoxia induce preconditioning in cardiomyocytes. J Biol Chem 1998;273:18092-8.

17. Haar L, Ren X, Liu Y, et al. Acute consumption of a high-fat diet prior to ischemia-reperfusion results in cardioprotection through $\mathrm{NF}-\kappa \mathrm{B}-$ dependent regulation of autophagic pathways. Am J Physiol Heart Circ Physiol 2014;307:H1705-13.

18. Guarnieri AR, Anthony SR, Gozdiff A, et al. Adipocytespecific deletion of HuR induces spontaneous cardiac hypertrophy and fibrosis. Am J Physiol Heart Circ Physiol 2021;321:H228-41.

19. Tranter M, Ren X, Forde T, et al. NF-kappaB driven cardioprotective gene programs; Hsp70.3 and cardioprotection after late ischemic preconditioning. J Mol Cell Cardiol 2010;49:664-72.

20. Smiley D, Smith MA, Carreira V, et al. Increased fibrosis and progression to heart failure in MRL mice following ischemia/reperfusion injury. Cardiovasc Pathol 2014;23:327-34.

21. Tranter M, Liu Y, He S, et al. In vivo delivery of nucleic acids via glycopolymer vehicles affords therapeutic infarct size reduction in vivo. Mol Ther 2012;20:601-8.

doi: 10.21037/exrna-21-31

Cite this article as: Anthony SR, Tranter M. Metabolically stressed adipocytes: mediators of cardioprotection via extracellular vesicle-mediated transport of oxidatively damaged mitochondria. ExRNA 2022;4:3. 